\title{
HVMANITAS
}

\section{"A mais bela brincadeira das musas": poesia e verdade em Baquíliades}

Autor(es): $\quad$ Várzeas, Marta

Publicado por: Imprensa da Universidade de Coimbra

URL

persistente:

URl:http://hdl.handle.net/10316.2/27381

DOI:

DOI:http://dx.doi.org/10.14195/2183-1718_64_1

Accessed : $\quad$ 26-Apr-2023 12:47:20

A navegação consulta e descarregamento dos títulos inseridos nas Bibliotecas Digitais UC Digitalis, UC Pombalina e UC Impactum, pressupõem a aceitação plena e sem reservas dos Termos e Condições de Uso destas Bibliotecas Digitais, disponíveis em https://digitalis.uc.pt/pt-pt/termos.

Conforme exposto nos referidos Termos e Condições de Uso, o descarregamento de títulos de acesso restrito requer uma licença válida de autorização devendo o utilizador aceder ao(s) documento(s) a partir de um endereço de IP da instituição detentora da supramencionada licença.

Ao utilizador é apenas permitido o descarregamento para uso pessoal, pelo que o emprego do(s) título(s) descarregado(s) para outro fim, designadamente comercial, carece de autorização do respetivo autor ou editor da obra.

Na medida em que todas as obras da UC Digitalis se encontram protegidas pelo Código do Direito de Autor e Direitos Conexos e demais legislação aplicável, toda a cópia, parcial ou total, deste documento, nos casos em que é legalmente admitida, deverá conter ou fazer-se acompanhar por este aviso. 
humanitas

\section{Vol. LXIV \\ 2012}

IMPRENSA DA UNIVERSIDADE DE COIMBRA

COIMBRA UNIVERSITY PRESS 


\title{
"A MAIS BELA BRINCADEIRA DAS MUSAS": POESIA E VERDADE EM BAQUÍLIDES
}

\author{
MARTA VÁRZEAS \\ Universidade do Porto
}

\section{Resumo}

Na longa história daquilo a que Platão haveria de chamar 'o antigo debate entre poesia e filosofia', o problema central que enformou a polémica contra os poetas foi o da verdade. Este é, no universo poético de Píndaro, um conceito nuclear, pois o poeta assume a função profética de trazer à luz a essência espiritual da arete. Em Baquílides, porém, a verdade "é da mesma cidade dos deuses", mas o poeta não parece tão confiante na possibilidade de aceder ao seu conhecimento. Em termos poéticos, o domínio em que se move é o da doxa, e daí o seu interesse pela acção humana concreta, sem a qual, em última análise, não existiria o canto.

Palavras-chave: verdade, poesia, Baquílides, Píndaro, epinício.

\section{Abstract}

In the long history of what Plato would later call "the ancient debate between poetry and philosophy" truth was in the very centre of the polemic against poets. In Pindar's poetic universe truth is a nuclear concept and the poet assumes his prophetic function of bringing to light the spiritual essence of arete. But in Bacchylides truth "is of the same city as the gods", and the poet doesn't seem so confident in the possibility of achieving true knowledge. His poetic domain is doxa's, and that explains his interest for the concrete human action, for without it song wouldn't even exist.

Key-words: truth, poetry, Bacchylides, Pindar, epinikion. 
Na longa história daquilo a que Platão haveria de chamar 'o debate entre poesia e filosofia', mas que, como sabemos, começou muito antes do aparecimento dos primeiros filósofos, o problema central que enformou a polémica contra os poetas foi o da verdade. E desde que este problema tomou forma em Hesíodo pela primeira vez, tanto quanto sabemos, não mais deixou de inquietar todos aqueles que cultivavam os jardins das Graças e que, por isso mesmo, se tinham habituado a gozar de um estatuto de autoridade que ia sendo posto em causa. No tempo de Píndaro e de Baquílides a questão era candente, e cada vez mais se adensava a competição pela supremacia na educação da pólis entre poetas, pensadores e os mestres daquela nova arte que ia ganhando terreno, a retórica. Ambos os poetas viveram num complexo tempo de mudanças - políticas, económicas, culturais, ideológicas - mas as marcas que essas circunstâncias deixaram no trabalho poético de cada um deles revestiram formas muito distintas.

Apesar de ambos afirmarem a ideia tradicional de que o canto faz perdurar na memória dos homens a excelência dos grandes feitos, para Píndaro a poesia cumpre uma função de revelação, na medida em que procura trazer à luz e dar a ver a essência espiritual da arete $^{l}$. A poesia é sentida como um saber e uma sabedoria (sophia é palavra cara a Píndaro para referir a sua arte $)^{2}$ em constante luta contra a ignorância que é insensível à manifestação do mistério do mundo. O poeta é, pois, um profeta ${ }^{3}$ que, assistido pela Musa, ilumina e ordena os dados do mundo e os reconduz à sua essência primordial, que o mesmo é dizer, à sua verdade.

Mas não é apenas neste sentido filosófico, quase parmenideano, que se pode falar da noção de verdade poética em Píndaro. Numa linha quiçá mais próxima de Hesíodo também ele assume e defende a sua própria singularidade, numa clara tomada de posição relativamente à tradição poética grega. Embora em alguns passos das Odes não enjeite as lições dos seus antecessores - afirmando seguir caminhos já antes descobertos (N. 6 . 52-53), elogiando os versos daqueles que deram a conhecer famosos heróis do passado (P. 3. 112-114), lembrando ditos de Homero (P. 4. 277-278), ou chegando mesmo a desejar igualá-lo (I. 4. 61-63) - a verdade é que, de

1 Sobre a poesia como lugar de revelação e de iluminação, combatendo a cegueira dos homens, vide, e.g., Péan 7; O. 7. 11-12.

2 Cf. Bowra 19644.

3 Cf. frs. 137 e 150 Snell-Mahler. Sobre este aspecto da poesia de Píndaro vide Duchemin 1955. 
uma maneira geral, o poeta prefere demarcar-se dos seus rivais de ofício e de uma poesia sem qualquer referencial ético, aspirando a um lugar de proeminência na arte. Isto nota-se mais claramente ao nível mitopoiético, quando rejeita anteriores versões de mitos, de acordo com um critério de verdade que não se compadece com as histórias mirabolantes, esquecidas daquele que deveria ser o objectivo primeiro do canto: o de exaltar o que é digno de louvor no mundo e censurar o que não é. Assim se justificam as modificações introduzidas no mito de Pélops e Tântalo da $1^{\text {a }}$ Olímpica. Aí se refere expressamente a possibilidade de as histórias contadas pelos poetas excederem os limites do verdadeiro, pois o deleite que elas proporcionam induz os homens a acreditarem em mentiras $\left(\mathrm{Ol}\right.$. 1.28-34) ${ }^{4}$.

Idêntica postura crítica surge na $7^{a}$ Nemeia (20-22). Aí, para exemplificar o poder glorificador do canto poético, recorda a figura de Ulisses que, por obra de Homero, 'o de doces palavras', alcançou renome maior do que lhe era devido. É que, conforme diz,

iludindo com mitos, a arte engana; pois a grande turba dos homens tem um coração cego.

Consciente da cegueira dos homens, incapazes de destrinçar o verdadeiro do falso nas histórias que ouvem, Píndaro só pode enveredar por uma poesia de conteúdo ético, procurando com as suas composições míticas não, como na epopeia, uma verdade supostamente factual, ou o registo supostamente fidedigno do que aconteceu, mas um sentido de verdade e de justiça universais com as quais o próprio canto se deve harmonizar, louvando o louvável e censurando o censurável ${ }^{5}$. Se a narração dos mitos ancestrais estivera sempre ao cuidado dos aedos, e se, no caso dos epinícios, como tudo leva a crer, ela fazia parte das convenções do género, Píndaro parece ter encontrado nesse elemento convencional caminho fértil para exercitar

4 Em Ol. 10. 1-6 o poeta fala da verdade como sendo filha de Zeus e afirma que é a sua mão correctora (ortha cheri), que o impede de dizer falsidades.

5 Neste sentido, o poeta é um "fazedor de mitos", e a sua verdade não deixa de ser fundamentalmente, como nota Segal (1986: 66), uma "construção mítica". Que Píndaro, de facto, não parece ter qualquer preocupação de fidelidade às narrativas tradicionais, demonstra-o a liberdade com que altera a sua própria versão de um mesmo mito em odes distintas. Veja-se o exemplo da união de Zeus com Alcmena: na $10^{a}$ Nemeia o deus surge disfarçado de Anfitrião, e na $7^{a}$ Ístmica sob a forma de neve de ouro, num claro cruzamento com o mito de Dânae. Vide Várzeas 2006216. 
a sua sophia e para demonstrar de que modo se pode compor uma poesia verdadeira.

Baquílides move-se num outro terreno. Quando comparados com Píndaro, os epinícios baquilideanos aparentam ter um mais alto grau de convencionalidade. E não me refiro às narrações míticas, um dos campos em que o poeta se mostra até mais criativo ${ }^{6}$, mas sobretudo ao uso artificial dos topoi que faziam parte da retórica dos cantos de vitória. É que se, às mãos do poeta tebano, aquilo que poderia ser um espartilho, isto é, as convenções de género, se transforma em matéria poética e reflexiva do mais alto nível, Baquílides parece mais concentrado na criação de um objecto estético que seja fonte de deleite e de prazer, sem aspirar a ser um mestre da verdade, para utilizar a expressão feliz de Marcel Détiènne ${ }^{7}$, mas tão somente a exaltar com simplicidade e beleza as acções dos homens concretos que são, afinal, a verdadeira razão de ser do canto.

Ao contrário de Píndaro, Baquílides não tece grandes considerações acerca da sua arte. E se existe uma arte poética baquilideana ela deduz-se fundamentalmente da sua prática. Em alguns passos, porém, é possível vislumbrar uma tomada de posição relativamente à questão das relações entre poesia e verdade, porquanto o próprio termo alatheia surge ligado, à primeira vista de forma muito convencional, ao canto de louvor. O vocábulo aparece nas odes cinco vezes: três em dativo, regido da preposição sun e, dessas, duas estão delimitadas por um complemento em genitivo. Apesar de pouco significativo em termos de quantidade, este uso mecânico da palavra, por si só, poderá dizer alguma coisa sobre o seu alcance semântico e conceptual. ${ }^{8}$ Todavia sinais contrários emergem de uma leitura mais atenta, pelo menos em dois passos - um na ode 3 , outro na ode 9 - constituindo tal repetição uma espécie de repto lançado ao nosso trabalho interpretativo.

6 Sobre alguns dos aspectos da arte baquilideana de narrar, vide Burnett 1985; Segal 1976; Carey 1980.

7 Este é o título da conhecida obra do helenista francês, citada na nota seguinte.

8 Nos epinícios de Píndaro a palavra alatheia surge apenas oito vezes, o que, tendo em conta a desproporção quantitativa entre a obra conhecida deste autor e a de Baquílides, pode significar um maior interesse por parte do segundo neste vocábulo em particular. $\mathrm{O}$ uso do substantivo abstracto não era muito frequente, havendo uma maior preferência pelo adjectivo ou por outros vocábulos e expressões semanticamente afins. Por isso me parece significativo que Baquílides recorra a alatheia no contexto das escassas referências à arte poética, utilizando o vocábulo desta maneira quase formular, como que a chamar a atenção para ela. Sobre os termos usados para exprimir as noções do falso e do verdadeiro e a sua evolução na Grécia antiga, vide Levêt 1976 e Détiènne 1981. 
Comecemos pela Ode 3, composta em honra de Hierão de Siracusa. São os versos finais que aqui interessam (88-96):

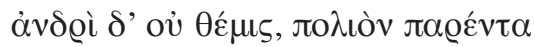

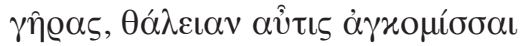

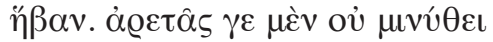

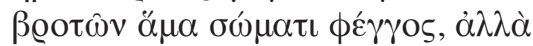

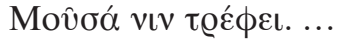

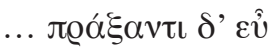

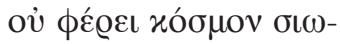

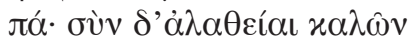

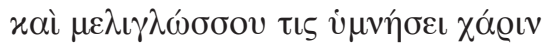

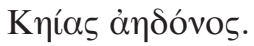

Mas ao homem não é possível pôr de lado

as cãs da velhice e recuperar a florida

juventude. Porém a luz da excelência

não diminui juntamente com o corpo mortal, mas

a Musa alimenta-a. (...)

Para quem realiza boas acções

não traz beleza

o silêncio. Mas com a verdade das coisas belas,

cantar-se-á também a graça

do rouxinol de Céos de língua de mel. ${ }^{9}$

9 A tradução destes versos não é consensual, e a polémica centra-se principalmente

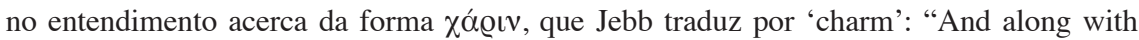
thy genuine glories men shall praise also the charm of the sweet singer, the nightingale of Ceos". Já Maehler (2004: 98-99) defende, na esteira de Fraenkel, que, com esta palavra, o poeta se refere à própria ode, enquanto dádiva de amizade a Hierão, o destinatário, e sugere a tradução: "“with the truth of your successes, men will sing the gift of the Kean nightingale.' Como se vê na tradução acima, sigo a proposta de Jebb. Idêntica opção é a de Lourenço (2005: 83) Uma outra interpretação deste passo, talvez um pouco arrevesada e sem grande vantagem para a compreensão das ideias da ode, encontra-se em Woodbury 1969. 
Como é fácil verificar, nestes versos o poeta repete ideias e até imagens tradicionais acerca da função do canto poético, como forma de eternizar a "luz da aretê", e como adorno - kosmon - para o vencedor; no entanto, é às coisas belas, ou seja, aos feitos ilustres dos homens que ele associa a alatheia. A verdade parece ser, portanto, intrínseca aos actos, talvez porque é nos actos que ela se manifesta, pondo a descoberto, de acordo com o significado da palavra em grego, a excelência humana. Os homens revelam-se na acção, e só assim mostram aquela parte da sua verdade - a grandeza - que, de outro modo, ficaria oculta por baixo da sua natureza mortal. As palavras não são, pois, como em Píndaro, o lugar de revelação da essência da arete, mas apenas o meio de a anunciar, impedindo o seu esquecimento. E o papel do poeta-rouxinol é precisamente o de, com a doçura das palavras e a delicada harmonia da música, glorificar os vencedores, dando início a um processo que outros, tocados pela mesma beleza, hão-de retomar e repetir.

Já na ode 5 o canto de louvor surge como um imperativo da própria verdade - alatheias charin - implicitamente apresentada como contraponto do phthonos, essa inveja maledicente que dificulta a propagação dos feitos ilustres $(187-190)^{10}$ :

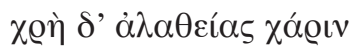

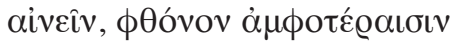

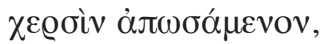

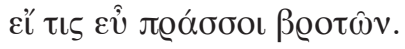

Forçoso é, mercê da verdade,

afastar com ambas as mãos

a inveja e louvar quem

dentre os mortais chegar ao êxito.

Quer dizer, sendo a inveja uma força de encobrimento dos actos humanos, na medida em que palavras difamadoras são a própria antítese do louvor, a verdade, que os põe a descoberto, precisa do canto como uma espécie de antídoto para combater o efeito destruidor do phthonos. Curioso 2009 .

10 Sobre o conceito de phthonos e o seu valor nas odes de Píndaro, vide Várzeas 
é que, como mostra a sequência do poema, é na própria tradição poética que Baquílides se apoia para justificar o seu papel de proclamador das boas acções (191-196) ${ }^{11}$ :

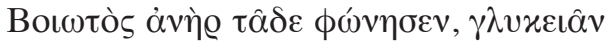

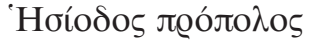

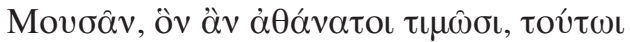

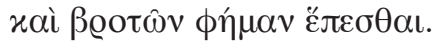

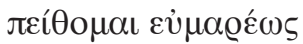

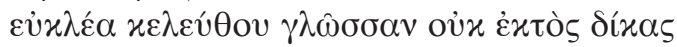

$\pi \varepsilon ́ \mu \pi \varepsilon เ v ' \mathrm{I} \mathrm{\varepsilon} \varrho \omega v$.

Um homem da Beócia, Hesíodo, servidor das doces

Musas, assim disse: "àquele a quem os deuses

honram segue a boa fama dos homens".

Facilmente me deixo persuadir

para mandar a Hierão um discurso honroso

sem me desviar do recto caminho.

Este é o trabalho do poeta: assegurar a boa fama daqueles cujos altos feitos são, antes de mais, sinal do favor divino. E embora o próprio Hesíodo, ao que sabemos, não tenha composto cantos de louvor em honra dos homens, ele representa uma tradição de poesia que Baquílides se orgulha de continuar ${ }^{12}$.

Na Ode 8 encontramos o único passo em que a palavra alatheia se refere à qualidade verídica de uma proposição, à exactidão daquilo que se afirma. Para assegurar que os ouvintes acreditem no que vai afirmar acerca da singularidade das vitórias de Lipárion, o destinatário da ode, o poeta tem necessidade de fazer um juramento, pois, segundo diz, com a verdade brilha toda a coisa. Essa preocupação com a verdade é, portanto, de outra ordem, mas não deixa de ter na base a ideia, também ela convencional, de que só a verdade dos factos garante a perenidade do louvor. É que, como diz

11 A tradução dos versos desta ode é de Lourenço 2005.

12 A influência de Hesíodo é patente em alguns versos de Baquílides. Carey assinala, por exemplo, o início da Ode 11, que lhe parece poder ligar-se aos versos 384 sqq. de Teogonia. Cf. Carey 1980 226-227. Já Kirkwood (1966: 100) dá maior destaque à inspiração homérica na produção poética baquilideana. 
na Ode 13, em versos (205-209) de um saber tradicional de que o próprio Píndaro faz eco, a verdade gosta de vencer / e o tempo que tudo submete / exalta sempre o que é feito com beleza / enquanto a língua enganadora dos inimigos / enfraquece, invisivel.

Deixei para o fim a Ode 9, composta para Automedes de Fliunte. $\mathrm{Na}$ última tríade, nos versos finais da estrofe, e nos iniciais da antístrofe, afirma o poeta (82-87):

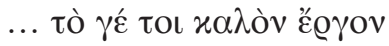

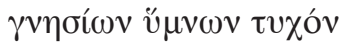

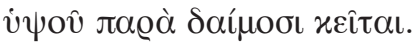

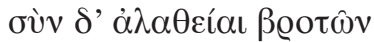

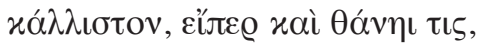

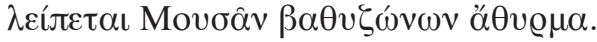

Quando um belo feito

encontra hinos de bom nascimento

é no alto, entre os deuses, que repousa.

Mas com a verdade dos mortais

a mais bela brincadeira das Musas de fina cintura

permanece, mesmo quando alguém morre.

O conjunto destes seis versos na sua construção bipartida, exprime dois movimentos de sentido contrário: por um lado, os hinos de bom nascimento, gnesion, elevam à categoria das divindades, dos daimones, um belo feito (to kalon ergon). Até aqui, nada de novo. A imagem é até muito pindárica, nesta referência metafórica ao bom nascimento, quer dizer, à genuinidade, se assim podemos dizer, dos hinos. Mas o que a seguir se afirma é que com a verdade dos mortais (sun d'alatheia broton) aquilo que para as Musas é um belo divertimento, uma bela brincadeira, athurma, não se extingue, mas permanece, não se restringindo à efemeridade do momento. Os hinos divinizam os feitos, mas a verdade humana, manifestada nesses feitos, torna a poesia imorredoura, fá-la descer do espaço dos deuses para 
o espaço dos homens, onde fica como seu memorial. Dizia Simónides ${ }^{13}$, tio de Baquílides, que as palavras são as imagens dos actos. Ora essa afirmação, que porventura traduz a defesa de um estilo pictórico, plástico que, de facto, encontramos na poesia baquilideana, pode ainda relacionar-se com uma visão da poesia epinícia como forma de reproduzir, fotografar, permita-se o anacronismo, a imagem do atleta vencedor. Não em termos ideais, como em Píndaro, mas como reflexo do próprio homem e da vitória particular que Baquílides, muito mais do que o seu rival, se esforça por descrever com colorido realismo e emoção. Aliás é bastante significativo, a meu ver, que uma palavra profusamente usada pelo poeta para se referir às suas odes, seja agalma, que significa 'adorno', 'ornamento', mas também 'estátua' e ‘imagem' em geral ${ }^{14}$.

Esta valorização da qualidade humana da verdade ${ }^{15}$ está talvez já patente, de forma subtil e ambígua na abertura da ode, que se me afigura particularmente intrigante. $O$ poeta pede às Graças a doxa, palavra com que inicia o poema e que surge destacadíssima pela interposição do vocativo que a separa de um adjectivo algo surpreendente neste contexto - peisimbroton 'que persuade os mortais'. Digo surpreendente, porque, se a doxa é geralmente, nas odes epinícias, 'a glória', 'a reputação', 'o renome'16, a sua qualificação como 'persuasora dos mortais' evoca, por contraste, e quase provocatoriamente, o universo do Poema de Parménides, onde a oposição entre doxa e aletheia está no centro de uma reflexão de alcance epistemológico com enormes repercussões no pensamente grego posterior. No seu Poema, Parménides chama à aletheia eupeitheos, 'fiável' ou 'fidedigna', e a única que deve persuadir os homens; e a respeito da doxa afirma não existir nela pistis alethes 'confiança verdadeira'. Ora se, salvas as devidas distâncias, é possível encontrar algumas afinidades ideológicas entre a poesia de Píndaro e o pensamento do filósofo de Eleia no que diz respeito à concepção de verdade, já Baquílides parece ter uma atitude um

13 Cf. Test. $47^{\text {a }}$ Campbell.

14 Outros exemplos da ocorrência desta palavra podem encontrar-se nas Odes 5, 3 e 10 .

15 Ao contrário, Píndaro censura, na ode Olímpica 1.28 sqq., a força daquilo a que chama broton phatis 'a fala dos homens', por esta se sobrepor ao alethe logon, isto é, ao 'discurso verdadeiro'.

16 Em Píndaro, salvo raras excepções, doxa significa 'reputação'. O significado de 'opinião' surge, porém, na ode Olímpica 6, assim o entendiam já os escoliastas antigos. Sobre este assunto vide Dover 1959. 
pouco mais ambígua, eu diria quase sofística, na medida em que procede a uma associação de termos que podem ser entendidos, de certa maneira, como antitéticos. Ao mesmo tempo que pede às Graças a doxa afirma-se 'divino profeta das Musas', mas aquele pedido retira a esta função profética a exigência de dizer o verdadeiro. $O$ poeta assume-se como profeta divino, mas não é a verdade dos deuses que ele vem anunciar. Em termos poéticos, o domínio em que se move é o da doxa, o da fama ${ }^{17}$ que é, antes de mais, palavra, e uma palavra que, relatando a verdade dos homens, não é, em si mesma, conhecimento verdadeiro, sophia, como em Píndaro, antes se assume como fonte de deleite e de prazer.

Se em Píndaro a poesia é fonte de visão e sem ela se mantêm cegas as mentes dos homens (Péan 7), para Baquílides a verdade "é da mesma cidade dos deuses", como diz um fragmento a ele incertamente atribuído ${ }^{18}$, mas o poeta não parece tão confiante como o seu rival tebano na possibilidade de aceder ao seu conhecimento ${ }^{19}$. Daí o seu interesse pela acção humana concreta, sem a qual, em última análise, não existiria o canto. É este interesse pelo homem, este comprometimento com o mundo dos mortais, como diz Mary Lefkowitz, que constitui uma das marcas da poesia de Baquílides a demonstrar a abertura do poeta ao seu tempo, um tempo marcado por uma intensa focalização no homem e nas suas realizações individuais e sociais. ${ }^{20}$

\section{Bibliografia:}

Balasch, M. (1971), "La teoría poética de Baquilides”, Helmantica 22: 369-386.

17 Poder-se-á pensar aqui também na acepção retórica do termo, ou seja, como sinónimo daquilo a que Aristóteles chamará o ethos do orador cuja credibilidade é fundamental no processo de persuasão. A palavra aparece, de facto, com esse sentido na Retórica a Alexandre 1428a e 1431b, na expressão doxa tou legontos. Seja como for, mesmo no sentido retórico, estamos longe daquilo que Píndaro pensava ser missão e até apanágio do poeta: o desvelamento da verdade.

18 Alatheia theon homopolis. Segundo Jebb, o fragmento é citado por Estobeu e a sua atribuição a Baquílides é conjectura de Bergk. Cf. Jebb 1905415.

19 Não é essa a opinião de Balasch 1971 384-386. Com efeito, este autor, destacando embora importantes diferenças entre Baquílides e Píndaro no que respeita à concepção da poesia e da função do poeta, defende que ambos assumem o dever de proclamar a verdade, e que esta possui, também em Baquílides, uma dimensão religiosa.

20 Lefkowitz 1969. Perspectiva semelhante é a de Carey (1980: 227), ao defender que Baquílides aborda a vitória de uma forma mais humana do que Píndaro, e assim explica o interesse do primeiro no relato mais detalhado e vívido das vitórias atléticas que celebra. 
Bowra, C. M. (1964), Pindar, Oxford.

Burnett, A. P. (1985), The Art of Bacchylides, Harvard University Press.

Carey, C. (1980), "Bacchylides experiments: Ode 11”, Mnemosyne 33: 225-243.

Détiènne, M. (1981), Les maîtres de verité dans la Grèce ancienne, Paris.

Dover, K. J. (1959), “Pindar Olympian Odes 6. 82-86”, CR 9: 194-196.

Duchemin, J. (1955), Pindare poète et prophète, Paris.

Jebb, R. (1905), Bacchylides. The Poems and Fragments, Cambridge.

Kirkwood, G. M. (1966), “The narrative art of Bacchylides” in Wallach, L. ed., The Classical Tradition: Literary and Historical Studies in Honor of Harry Caplan, Ithaca, NY, 98-114.

Lefkowitz, M.R. (1969), “Bacchylides' Ode 5: Imitation and originality”, HSCPh 73: 45-96.

Levêt, J.P. (1976), Le vrai et le faux dans la pensée archaïque grecque, Paris.

Lourenço, F. (2005), Poesia Grega de Álcman a Teócrito, Lisboa.

Lourenço, F. (org.) (2006), Ensaios sobre Píndaro, Lisboa, Cotovia.

Maehler, H. (1982, 1997), Die Lieder des Bakchylides, Leiden, 2 vols.

Maehler, H. (2004), Bacchylides: A Selection, Cambridge.

Segal, C. (1976), "Bacchylides reconsidered: epithets and the dynamics of lyric narrative", QUCC 22: 99-130.

Segal, C. (1986), "Naming, truth, and creation in the poetics of Pindar", Diacritics 16: 65-83.

Várzeas, M. (2006), "Neve de ouro: Ístmica VII" in Lourenço, F. (org.), Ensaios sobre Píndaro, Lisboa, Cotovia, 213-224.

Várzeas, M. (2009), "Inveja e emulação em Píndaro” in Pereira, B. F e Deserto, J. (eds.), Symbolon. Inveja e emulação, Porto, 19-28.

Woodbury, L. (1969), "Truth and the song: Bacchylides 3.96-98", Phoenix 23: 331-335. 